\title{
PENGARUH PERSEPSI KEMUDAHAN, MANFAAT DAN KEAMANAN TERHADAP KEPUTUSAN PEMBELIAN KARTU INDOMARET DI REST AREA KM 35 SENTUL KABUPATEN BOGOR
}

\author{
${ }^{1)}$ Dasmansyah Adyas, ${ }^{2)}$ Rika Ainurahmah \\ ${ }^{1)}$ Dosen Program Studi Manajemen, STIE Dewantara \\ J1. Raya Pemda Bojong Depok Baru III, Karadenan, Cibinong, Bogor, Jawa Barat 16913, Indonesia \\ Email: dasmansyah.adyas@dewantara.ac.id \\ ${ }^{2)}$ Alumni Program Studi Manajemen, STIE Dewantara \\ Jl. Raya Pemda Bojong Depok Baru III, Karadenan, Cibinong, Bogor, Jawa Barat 16913, Indonesia \\ Email: rika17ainurahmah@gmail.com
}

\begin{abstract}
The research method used is multiple linear regression analysis method, using simultaneous tests and partial test. The data used are primary and secondary data. Samples taken as many as 96 respondents using purposive sampling technique. The results of this study indicate that perceptions of ease, perceptions of benefits and perceptions of security, physical evidence, processes jointly influence the decision to purchase Indomaret cards by 0.406 or $40 \%$ ease, benefits and security is one of the processes of positive influence on consumer decisions. In partial test (t-test) it is known significantly with sig. Respectively 0,000 and 0,001 <from 0,05 and $t$ count value respectively 3,703,> t table values 1,66159, 1,787 and 3,588>t table values 1,66159. This shows that the variable perceived ease of use, perceived usefulness and security influence consumer decisions in purchasing Indomaret cards.
\end{abstract}

Keywords : Perception of Convenience, Benefits, Security, Decision to Purchase.

\section{ABSTRAK}

Metode penelitian yang di gunakan adalah metode analisis regresi linier berganda, dengan menggunakan uji simultan dan uji parsial. Data yang di gunakan adalah data primer dan sekunder. Sampel yang di ambil sebanyak 96 responden dengan menggunakan teknil purposive sampling. Hasil penelitian ini menunjukan bahwa persepsi kemudahan, persepsi manfaat dan persepsi keamanan, bukti fisik, proses secara bersama-sama berpengaruh terhadap keputusan pembelian kartu Indomaret sebesar 0,406 atau 40\% kemudahan, manfaat dan keamanan adalah salah satu proses pengaruh positif terhadap keputusan konsumen. Secara uji parsial (uji-t) di ketahui secara signifikan dengan nilai sig. Masing-masing 0,000 dan 0,001 < dari 0,05 dan nilai $t$ hitung masing-masing sebesar 3,703,> nilai t tabel 1,66159 , 1,787 dan $3,588>$ nilai $\mathrm{t}$ tabel 1,66159. Hal ini menunjukan bahwa variabel persepsi kemudahan, persepsi manfaat dan keamanan yang mempengaruhi keputusan konsumen dalam membeli kartu indomaret.

Kata kunci: Persepsi Kemudahan, Manfaat, Keamanan, Keputusan Pembelian.

\begin{tabular}{ll}
\hline 1. PENDAHULUAN PT Indomarco Prismata (Indomaret) \\
1.1 Latar Belakang & $\begin{array}{l}\text { bekerjasama dengan bank Mandiri dan } \\
\text { Indomaret ini adalah perusahaan yang }\end{array}$ \\
Indomaret bekerjasama untuk \\
mempunyai pemikiran mempermudah & $\begin{array}{l}\text { memperkenalkan kartu elekrtonik seperti } \\
\text { kartu Indomaret, etoll, card Gaz ke seluruh }\end{array}$ \\
konsumen untuk berbelanja semakin lama & wilayah Indonesia. \\
dan teknologi yang semakin canggih dan & Indomaret rest area stopan sentul ini \\
tidak mau ketinggalan zaman perusahaan & adalah toko yang paling banyak di jumpai \\
tertarik untuk mendalami dan memahami & pengunjung karena letaknya berada di \\
kebutuhan kosumennya dengan & dalam tol jagorawi km 35 karena rest area \\
mengeluarkan kartu Indomaret, kartu & banyaknya orang yang istirahat dan \\
elektronik atau sama seperti kartu emoney &
\end{tabular}


banyaknya yang singgah dan berbelanja sekedar membeli air dan tentunya top up kartu etollnya atau top up karena mudah dan aman tanpa repot untuk mengeluarkan uang receh dalam transaksi, macam macam kartu elektronik inilah sangat di butuhkan dan karena berada di dalam tol, kosumen yang datangpun konsumen yang tidak berlamalama rata-rata mempunyai bermacam-macam kartu elektronik atau menanyakan kartu elektronik untuk bertransaksi agar lebih efisien untuk berikut ini adalah data pengguna kartu elektronik di rest area stopan sentul :

Tabel 1. Data Penggunaan Kartu di Rest Area KM 35 Sentul

\begin{tabular}{|c|c|c|}
\hline $\begin{array}{c}\text { Nama } \\
\text { Kartu }\end{array}$ & $\begin{array}{c}\text { Rata-rata } \\
\text { Penggunaan } \\
\text { Perhari }\end{array}$ & $\begin{array}{c}\text { Akumulasi } \\
\text { Perbulan }\end{array}$ \\
\hline Flazz & Rp.1.092857 & Rp. 32.785 .700 \\
\hline Etoll Card & Rp.850.000 & Rp. 25.500 .000 \\
\hline $\begin{array}{c}\text { Indomaret } \\
\text { Card }\end{array}$ & Rp.650.000 & Rp. 19.500 .000 \\
\hline Brizzi & Rp.142,857 & Rp. 4.285 .714 \\
\hline t-cash & Rp.50.000 & Rp. 1500.000 \\
\hline
\end{tabular}

Tabel 2. Data Konsumen

\begin{tabular}{|c|c|c|}
\hline BULAN & $\begin{array}{c}\text { JUMLAH } \\
\text { KONSUMEN }\end{array}$ & PRESENTASE \\
\hline FEBRUARI & 765 & 32,5 \\
\hline MARET & 678 & 28,8 \\
\hline APRIL & 909 & 38,6 \\
\hline JUMLAH & 2352 & $100 \%$ \\
\hline \multicolumn{2}{|c|}{ Sumber * Indomaret Rest Area Km 35 }
\end{tabular}

sentul Kab Bogor

Dilihat dari data Tabel 1. bisa di lihat dari rata-rata penggunaan perharikartu indomaret berada di bawah jauh dari nilai rata-rata penggunaan kartu flash BCA dan bisa di lihat dari tabel 1.2 jumlah konsumen yang menggunakan kartu mengalami naik turun penggunaan

Keputusan pembelian adalah salah satu pengaruh dari penjualan suatu produk akan naik ataupun turun. Sedangkan faktor yang dapat mempengaruhi keputusan pem-belian antara lain:

Faktor pertama yang mempe-ngaruhi keputusan pembelian adalah Persepsi kemudahan. Persepsi Kemudahan ini sangat di perhatikan oleh konsumen. Konsumen ingin memiliki kemudahan saat bertransaksi dimanapun dan kapanpun tanpa adanya hambatan.

Faktor kedua yang dapat mempengaruhi keputusan pembelian adalah persepsi manfaat dalam pengambilan keputusan Persepsi manfaat merupakan salah satu pertimbangan penting, karena konsumen tentunya mengharapkan kartu yang di miliki mempunyai manfaat yang sangat membantu keseharian dan aktifitas keseharianya menjadi lebih efisien tau bermanfaat

Faktor ketiga yang dapat mempengaruhi keputusan pembeli-an adalah Persepsi keamanan. Di mana konsumen merasa aman memliki kartu Indomaret karena data atau uang yang di simpan dalam kartu tersebut memiliki keamanan yang cukup untuk memudahkan dalam transaksi.

\subsection{Rumusan Masalah}

Dari latar belakang masalah, perumusan dalam penelitian ini adalah sebagai berikut:

1. Apakah Persepsi kemudahan berpengaruh terhadap keputusan pembelian kartu Indomaret di Rest Area KM 35 Sentul Kabupaten Bogor?

2. Apakah Persepsi Manfaat berpengaruh terhadap keputusan pembelian kartu Indomaret di Rest Area KM 35 Sentul Kabupaten Bogor?

3. Apakah Persepsi Keamanan berpengaruh terhadap keputusan pembelian kartu Indomaret di Rest Area KM 35 Sentul Kabupaten Bogor?

4. Apakah Persepsi kemudahan, manfaat dan keamanan berpengaruh simultan terhadap keputusan pembelian Kartu 
Indomaret di Rest Area Km 35 Sentul Kabupaten Bogor?

\subsection{Tujuan Penelitian}

Tujuan yang ingin dicapai da-lam penelitian ini adalah sebagai berikut:

1. Untuk menganalisis pengaruh persepsi kemudahan terhadap keputusan pembelian kartu Indomaret di Rest Area Km 35 Sentul Kabupaten Bogor.

2. Untuk menganalisis pengaruh persepsi manfaat terhadap keputusan pembelian kartu Indomaret di Rest Area Km 35 Sentul Kabupaten Bogor.

3. Untuk menganalisis Pengaruh persepsi keamanan terhadap keputusan pembelian kartu Indomaret di Rest Area Km 35 Sentul Kabupaten Bogor.

4. Untuk mengetahui pengaruh persepsi kemudahan, persepsi manfaat dan persepsi keamanan secara simultan terhadap keputusan pembelian kartu di Rest Area Km 35 Sentul Kabupaten Bogor.

\section{TINJAUAN PUSTAKA}

\subsection{Landasan Teori}

\subsubsection{Kartu Indomaret}

Indomaret Card sebuah kartu nirsentuh (kartu tempel), hadir dalam 3 (tiga) pilihan kartu yang memudahkan transaksi harian konsumen. Transaksi konsumen menjadi lebih mudah dan praktis, konsumen tidak perlu membawa uang tunai dan direpotkan oleh uang kembalian. Indomaret Card bisa digunakan saat bertransaksi di merchant's yang melayani Indomeret Card.

\subsubsection{Persepsi Kemudahan (Percieved Ease of Use)}

Menurut (Andriyano, 2014) pengertian perspektid kemudahan memberikan indikasi bahwa suatu sistem di rancang bukan untuk menyulitkan pemakainya, akan tetapi penggunaan sistem justru mempermudah seseorang dalam menyelesaikan pekerjaannya.
Menurut Venkatesh dan Davis membagi indikator persepsi kemudahan menjadi berikut (Anendro, 2016)

a. Interaksi individu dengan sistem jelass dan mudahh di megerti (clear and understandable).

b. Tidak di buthkan banyak usaha untuk berinteraksi dengan sistem tersebut (does not require a lot of mental effort)

c. Sistem yang di gunkan mudah (easy to use).

d. Mudah mengoperasikan sistem sesuai dengan apa yang ingin individu kerjakan (easy to get the sistem to do what he/she wants to do).

\subsubsection{Persepsi Kemanfaatan (Percieved Usefulness)}

Menurutn Jogiyanto (Triani, 2016) perepsi manfaat (percieved Usefulness) didefinisikan sebagai tingkat dimana seseorang percaya bahwa menggunakan sytem tertentu dapat meningkatkan kinerjanya.

Menurut (Nurmalasari, 2018) indikator pengukur persepsi kemanfaatan terdiri dari :

a. Meningkatkan produktivitas.

b. Meningkatkan keefektifan dalam kehidupan sehari-hari.

c. Mengurangi waktu bertaransaksi.

d. Sangat bermanfaat.

\subsubsection{Persepsi Keamanan}

Menurut (Jebran dan Dipankar, 2012) mengindentifikasi bahwa kemanan, privasi dan risiko keselamatan yang di keluarkan yang dapat mempengaruhi persepsi pelanggan dari aktivitas umum perbankan bank umum. Tingkat keamanan ini di ukur dengan indikator tidak khawatir memberikan informasi, kepercayaan bahwa informasi di lindungi, dan kepercayaan bahwa informasi di lindungi bahwa keamanan uang yang ada dalam alat elekronik terjamin pada saat transaksi. 


\subsubsection{Keputusan Pembelian}

Menurut (Sangadji, 2013 :121) pengambilan keputusan konsumen adalah proses pengintegrasian yang mengombinasikan pengetahuan untuk mengevaluasi dua perilaku atau lebih, dan memilih salah satu di antaranya

\subsection{Definisi Operasional}

Tabel 3. Definisi Operasional

\begin{tabular}{|c|c|c|}
\hline Variabel & Indikator & Skala Ukur \\
\hline \multirow{3}{*}{$\begin{array}{l}\text { Persepsi } \\
\text { Kemudahan } \\
\text { (X1) }\end{array}$} & $\begin{array}{l}\text { Mudah } \\
\text { Dipelajari }\end{array}$ & \multirow{3}{*}{ Likert } \\
\hline & $\begin{array}{l}\text { Mudah } \\
\text { Dioperasikan }\end{array}$ & \\
\hline & $\begin{array}{l}\text { Mudah Menjadi } \\
\text { Mahir }\end{array}$ & \\
\hline \multirow{3}{*}{$\begin{array}{l}\text { Persepsi } \\
\text { Manfaat } \\
\quad(\mathrm{X} 2)\end{array}$} & $\begin{array}{l}\text { Meningkatkan } \\
\text { Efektifitas }\end{array}$ & \multirow{3}{*}{ Linkert } \\
\hline & Bermanfaat & \\
\hline & $\begin{array}{l}\text { Meningkatkan } \\
\text { Efisiensi }\end{array}$ & \\
\hline \multirow{2}{*}{$\begin{array}{l}\text { Persepsi } \\
\text { Keamanan } \\
\quad \text { (X3) }\end{array}$} & $\begin{array}{l}\text { Memberikan } \\
\text { Rasa Aman }\end{array}$ & \multirow{2}{*}{ Linkert } \\
\hline & $\begin{array}{l}\text { Keamanan saat } \\
\text { bertransaksi }\end{array}$ & \\
\hline \multirow{2}{*}{$\begin{array}{c}\text { Keputusan } \\
\text { Pembelian } \\
\text { (Y) }\end{array}$} & $\begin{array}{l}\text { Tingkat Minat } \\
\text { Membeli }\end{array}$ & \multirow{2}{*}{ Linkert } \\
\hline & $\begin{array}{l}\text { Tingkat } \\
\text { Kebutuhan }\end{array}$ & \\
\hline
\end{tabular}

\subsection{Kerangka Pemikiran}

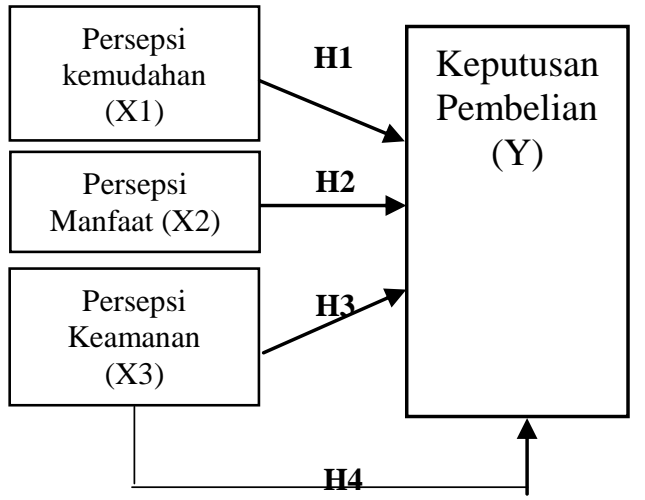

\section{Gambar 2. Kerangka Pemikiran}

\section{$2.4 \quad$ Hipotesis}

Hipotesis berperan sebagai pedoman pelaksanaan penelitian dan membantu membuat rancangan kesimpulan. Adapun hipotesis yang diajukan dalam penelitian ini adalah sebagai berikut:

$\mathrm{HO}=$ Tidak ada pengaruh persepsi kemudahan, persepsi manfaat dan persepsi keamanan baik secara parsial maupun simultan terhadap keputusan pembelian kartu indomaret.

H1 = 0 Ada pengaruh persepsi kemudahan terhadap keputusan pembelian kartu Indomaret.

$\mathrm{H} 2=0 \quad$ Ada pengaruh persepsi manfaat terhadap keputusan pembelian kartu Indomaret.

$\mathrm{H} 3=0$ Ada pengaruh persepsi keamanan terhadap keputusan pembelian kartu Indomaret.

$\mathrm{H} 4=0$ Ada pengaruh persepsi kemudahan, persepsi manfaat dan persepsi keamanan secara simultan terhadap keputusan pembelian kartu Indomaret.

\section{METODE PENELITIAN}

\subsection{Jenis Penelitian}

Penelitian ini merupakan jenis penelitian kuantitatif. Penelitian ini termasuk jenis penelitian kuantitatif kausalitas.

\subsection{Variabel Penelitian}

Variabel yang digunakan dalam penelitian ini adalah variabel independen. Persepsi kemudahan (X1), Manfaat (X2), dan Keamanan (X3). Sedangkan variabel dependen dalam penelitian ini adalah Keputusan Pembelian Kartu (Y).

\subsection{Lokasi Penelitian}

Lokasi yang digunakan dalam penelitian ini adalah Indomaret di Rest Area Sentul KM 35 Kadumanggu Tol Jagorawi.

\subsection{Waktu Penelitian}

Penelitian ini dilakukan selama periode Februari sampai Mei 2018.

\subsection{Objek Penelitian}

Adapun objek penelitian dalam penjualan Indomaret card, yaitu Akuisi 
pelanggan, kepuasan pelanggan, bisnis Internal serta pembelajaran dan pertumbuhan pada Indomaret Rest Area tol Jagorawi KM 35. Subjek penelitian adalah benda, hal, atau orang yang dituju untuk diteliti dalam sebuah penelitian. Adapun subjek penelitian ini adalah karyawan dan konsumen yang membeli Indomaret card di Rest Area stopan Sentul Kabupaten Bogor.

\subsection{Populasi dan Sampel}

\subsubsection{Populasi}

Dalam penelitian ini yang dijadikan populasi adalah konsumen yang berbelanja menggunakan kartu Indomaret. di Indomaret Rest Area Stopan Sentul Kabupaten Bogor KM 35 Kadumanggu Tol Jagorawi Tercatat sebanyak 2.352 orang yang berbelanja menggunakan kartu Indomaret di hitung berdasarkan data selama 3 bulan akhir ini.

\subsubsection{Sampel}

Sampel yang digunakan dalam penelitian ini adalah konsumen yang menggunakan kartu indomaret di Rest Area stopan Sentul. Untuk perhitungan sampel pada populasi terdefinisi dengan jelas, peneliti menggunakan rumus penentuan sampel oleh Slovin yang terjadi pada Indomaret rest area yaitu mengikuti formula:

$$
n=\frac{N}{1+N e^{2}}
$$

\section{Keterangan :}

$\mathrm{n}$ = Jumlah sampel yang dibutuhkan dari populasi

$\mathrm{N}=$ Populasi dari keseluruhan konsumen yang berkunjung berbelanja ke Indomaret rest area stopan sentul ( 2352) Orang.

$\mathrm{e}=$ Margin of error (10\%)

Berdasarkan formula tersebut maka dapat dicari jumlah sampel sebagai berikut : $n=\frac{2.352}{1+2.352\left(0,1^{2}\right)}=95.9$

$=96$ Orang

Sampel yang dibutuhkan dalam penelitian ini sebanyak 100 orang untuk menduga populasi.

\subsection{Teknik Pengumpulan Data}

Data yang digunakan dalam penelitian ini adalah data primer dan data sekunder.

1. Data Primer

Menurut Umar Husain (2001:69) merupakan data yang diperoleh dari sumber pertama baik dari individu atau perorangan seperti hasil pengisian wawancara atau pengisian kuesioner. Data pimer dalam penelitian ini berupa penyebaran kuesioner kepada pelanggan dan wawancara.

2. Data Sekunder

Menurut Umar Husain (2001:69) merupakan data primer yang telah diolah lebih lanjut dan disajikan baik oleh pengambil data primer maupun oleh pihak lain. Data sekunder dalam penelitian ini berupa data pengujung perusahaan, struktur organisasi perusahaan.

\subsection{Teknik Analisis Data}

Berikut Teknik Analisis Data yang akan digunakan adalah :

a. Uji Validitas

b. Uji Reliabilitas

c. Uji Asumsi Klasik

1. Uji Normalitas

2. Uji Multikolinearitas

3. Uji Heterokedastisitas

d. Uji Analisa Data

1. Analisis Regresi Linier Berganda

2. Koefisien Determinasi

e. Uji Hipotesis

1. Uji Parsial (Uji t)

2. Uji Silmutan (Uji F)

\section{HASIL DAN PEMBAHASAN}

\subsection{Uji Validitas}

Uji validitas digunakan untuk mengukur sah atau valid tidaknya suatu kuesioner. Dalam penentuan layak atau 
tidaknya suatu item yang digunakan, dilakukan uji sig-nifikansi koefisien korelasi pada taraf signifikansi 0,1 . Suatu data dikatakan valid apabila $r$ hitung $\geq r$ tabel.

Tabel 4. Hasil Uji Validitas

\begin{tabular}{|c|c|c|c|}
\hline Variabel & $\begin{array}{c}\mathbf{r} \\
\text { hitung }\end{array}$ & $\begin{array}{c}\mathbf{r} \\
\text { tabel }\end{array}$ & Keterangan \\
\hline \multicolumn{5}{|c|}{ Persepsi Kemudahan (X1) } \\
\hline X.1.1 & 0,875 & 0,1689 & Valid \\
\hline X.1.2 & 0,938 & 0,1689 & Valid \\
\hline X.1.3 & 0,886 & 0,1689 & Valid \\
\hline Persepsi Manfaat (X2) \\
\hline X.2.1 & 0,804 & 0,1689 & Valid \\
\hline X.2.2 & 0,809 & 0,1689 & Valid \\
\hline X.2.3 & 0,843 & 0,1689 & Valid \\
\hline Persepsi Keamanan $(X 3)$ \\
\hline X.3.1 & 0,88 & 0,1689 & Valid \\
\hline X.3.2 & 0,886 & 0,1689 & Valid \\
\hline X.3.3 & 0,897 & 0,1689 & Valid \\
\hline Keputusan Pembelian (Y) \\
\hline Y.1 & 0,692 & 0,1689 & Valid \\
\hline Y.2 & 0,693 & 0,1689 & Valid \\
\hline
\end{tabular}

Sumber : Pengolahan Data, 2019

Berdasarkan data diatas nilai $r$ tabel jumlah responden sebanyak 96 responden dengan taraf signifikansi 0,1 dan $\mathrm{df}=100$ sehingga memperoleh nilai sebesar 0,1689 . Berdasarkan hasil pengujian uji validitas Persepsi Kemudahan, Manfaat, Keamanan dan Keputusan Pembelian (Y) semua item pertanyaan kuesioner dinyatakan valid.

\subsection{Uji Reliabilitas}

Pengujian reliabilitas dilakukan sebagai salah satu pengukuran yang menunjukkan konsistensi dan stabilitas dari suatu skor (skala pengukuran). Dalam pengukuran relibilitas, kuesioner dinyatakan reliabel apabila nilai Cronbach's Alpha lebih besar atau sama dengan 0,60 .
Tabel 5. Hasil Uji Reliabilitas

\begin{tabular}{|c|c|}
\hline \multicolumn{2}{|c|}{ Reliability Statistics } \\
\hline Cronbach's Alpha & N of Items \\
\hline 0,797 & 2 \\
\hline
\end{tabular}

Sumber : Pengolahan Data, 2019

Dari hasil uji realiabilitas di atas dapat di lihat bahwa nilai Cronchbach's alpha adalah 0,797, hasil tersebut lebih besar dari 0,60 maka dapat di simpulkan bahwa intrument tersebut sudah reliabel.

\subsection{Uji Asumsi Klasik}

\subsubsection{Uji Normalitas}

Uji normalitas bertujuan untuk menguji apakah dalam model regresi, variabel dependen dan independen keduanya mempunyai distribusi normal atau tidak. Uji normalitas menggunakan uji Kolmogorov-Smirnov, dengan uji ini dapat diketahui data yang digunakan berdistribusi normal atau tidak. Apabila nilai signifikansi $>0.1$, maka data tersebut berdistribusi normal dan begitu juga sebaliknya.

\section{Tabel 6. Hasil Uji Normalitas}

One-Sample Kolmogorov-Smirnov Test

\begin{tabular}{|ll|r|}
\hline \multicolumn{1}{|c|}{} & \multicolumn{2}{|c|}{$\begin{array}{c}\text { Unstandardized } \\
\text { Residual }\end{array}$} \\
\hline $\mathrm{N}$ & Mean & 96 \\
Normal & Std. &, 0000000 \\
Parameters ${ }^{\mathrm{a}, \mathrm{b}}$ & Deviation &, 75954414 \\
Most Extreme & Absolute &, 045 \\
Differences & Positive &, 042 \\
& Negative &,- 045 \\
Test Statistic & &, 045 \\
Asymp. Sig. (2-tailed) &, $200^{\mathrm{c}, \mathrm{d}}$ \\
\hline a. Test distribution is Normal. \\
b. Calculated from data.
\end{tabular}

Sumber : Pengolahan Data, 2019

Berdasarkan hasil uji normalitas menggunakan uji Komogorov-Smirnov pada table diatas, di tujukan hubungan normal. Berdasarkan hasil output SPSS signifikasi 0,200 dan nilai Asymp.sig ( 2-tailed ) jauh 
di atas a $=0,1$, hal ini (H0) diterima atau berdistribusi secara normal.

\subsubsection{Uji Multikolinearitas}

Uji multikolinieritas digunakan untuk mengetahui apakah antara variabel bebas terjadi multikolinieritas atau tidak. Uji yang digunakan dengan teknik korelasi product moment. Interpretasinya adalah jika harga interkorelasi antar variabel bebas lebih dari atau sama dengan 0,800 berarti antar variabel tersebut terjadi multikolinieritas, demikian juga sebaliknya atau dengan melihat nilai VIF (Varian Inflation Factor) dan Toleransi pada proses regresi biasa, jika keduanya mendekati 1 atau besaran VIF kurang dari 10 maka model tidak terkena multikolonieritas. Hasil pengujian multikolonieritas dapat dilihat di tabel di bawah ini :

Tabel 7. Hasil Uji Mulitikolinearitas

\begin{tabular}{|c|c|c|}
\hline Variabel & Toleransi & VIF \\
\hline $\mathrm{X} 1$ & 0,735 & 1,361 \\
\hline $\mathrm{X} 2$ & 0,800 & 1,250 \\
\hline $\mathrm{X} 3$ & 0,766 & 1,305 \\
\hline
\end{tabular}

Sumber : Pengolahan Data, 2019

Dari hasil uji multikolonearitas di atas semua nilai Tolerance variabel independen $>0,1$ atau nilai $V I F<10$ yang mengindikasi tidak terjadinya multikolinearitas.

\subsubsection{Uji Heterokedastisitas}

Uji Heteroskedastisitas bertujuan menguji apakah dalam model regresi terjadi ketidaksamaan variance dari residual satu pengamatan ke pengamatan lain.
Tabel 8. Hasil Uji Glejser

\begin{tabular}{|c|c|c|}
\hline Variabel & Sig & Kesimpulan \\
\hline $\begin{array}{c}\text { Persepsi } \\
\text { Kemudahan } \\
(\mathrm{X} 1)\end{array}$ & 0,461 & $\begin{array}{c}\text { Tidak terjadi } \\
\text { heteroskedasitas }\end{array}$ \\
\hline $\begin{array}{c}\text { Persepsi } \\
\text { Manfaat (X2) }\end{array}$ & 0,335 & $\begin{array}{c}\text { Tidak terjadi } \\
\text { heteroskedasitas }\end{array}$ \\
\hline $\begin{array}{c}\text { Persepsi } \\
\text { Keamanan } \\
(\mathrm{X} 3)\end{array}$ & 0,81 & $\begin{array}{c}\text { Tidak terjadi } \\
\text { heteroskedasitas }\end{array}$ \\
\hline
\end{tabular}

Sumber : Pengolahan Data, 2019

Berdasarkan hasil di atas dapat di simpulkan bahwa persepsi kemudahan, persepsi manfaat dan persepsi keamanan semua variabel tidak terjadi heteroskedasitas bisa di lihat dari nilai sig > 0,1 .

\subsection{Uji Analisis Regresi Linier Berganda}

Analisis regresi linier berganda bertujuan untuk mengetahui pengaruh Persepsi kemudahan, manfaat dan keamanan terhadap keputusan pembelian. Hasil pengujian uji regresi linier berganda di peroleh nilai koefisien onstan sebesar 2,902 Persepsi Kemudahan (X1) sebesar 0,168, koefisien Persepsi Manfaat (X2) sebesar 0,098, koefisien Persepsi Keamanan (X3) sebesar 0,168.

Tabel 9. Hasil Uji Analisis Regresi Linier Berganda

\begin{tabular}{|c|c|c|c|c|c|c|}
\hline \multicolumn{7}{|c|}{ Coefficients $^{\mathrm{a}}$} \\
\hline \multirow{2}{*}{\multicolumn{2}{|c|}{ Model }} & \multicolumn{2}{|c|}{$\begin{array}{l}\text { Unstandardized } \\
\text { Coefficients }\end{array}$} & \multirow{2}{*}{$\begin{array}{c}\text { Standardized } \\
\text { Coefficients } \\
\text { Beta }\end{array}$} & \multirow{2}{*}{$t$} & \multirow{2}{*}{ Sig. } \\
\hline & & B & $\begin{array}{l}\text { Std. } \\
\text { Error }\end{array}$ & & & \\
\hline \multirow[t]{4}{*}{1} & (Constant) & 2,902 &, 692 & & 4,196 &, 000 \\
\hline & $\mathrm{x} 1$ &, 168 &, 045 &, 342 & 3,703 &, 000 \\
\hline & $\mathrm{x} 2$ & 098 &, 055 & , 158 & 1,787 & 077 \\
\hline & $\mathrm{X} 3$ & , 168 & ,047 & ,324 & 3,588 &, 001 \\
\hline
\end{tabular}

Sumber : Pengolahan Data, 2019

Berdasarkan hasil tersebut, persamaan regresi dapat dirumuskan sebagai berikut:

$$
\begin{aligned}
& Y=a+b_{1} X_{1}+b_{2} X_{2}+b_{3} X_{3} \\
& Y=2,902+0,168+0,098+0,168 X 3
\end{aligned}
$$


Dimana :

$\mathrm{Y}=$ Keputusan Pembelian

$\mathrm{X} 1=$ Persepsi Kemudahan

$\mathrm{X} 2=$ Persepsi Manfaat

X3 = Persepsi Keamanan

Keterangan:

$\mathrm{a}=2,902$ berarti bahwa nilai kon-stanta Persepsi kemudahan, persepsi manfaat, dan persepsi keamanan dianggap konstan terhadap keputusan pembeliannya, maka ke-putusan pembelian sebesar 2,902

$\mathrm{b}_{1}=$ Koefisien regresi Persepsi kemudahan sebesar 0,168 menyatakan bahwa apabila persepsi kemudahan meningkat sebesar satu satuan, maka keputusan pembelian akan meningkat sebesar 0,168 satuan.

$\mathrm{b}_{2}=$ Koefisien regresi Persepsi manfaat sebe-sar 0,098 menyatakan bahwa apa-bila persepsi manfaat meningkat sebesar satu satuan, maka keputusan pembelian akan meningkat sebe-sar 0,098 satuan.

$\mathrm{b}_{3}=$ Koefisien regresi Persepsi keamanan sebesar 0,168 menyatakan bahwa apabila persepsi kemudahan meningkat se-besar satu satuan, maka keputusan pembelian akan meningkat sebesar 0,168 satuan.

Berdasarkan hasil penelitian analisis Linier Berganda Persepsi Kemudahan, Perepsi Manfaat dan Persepsi Keamanan bahwa ada pengaruh positif terhadap Keputusan Pembelian kartu Indomaret di Rest Area Km 35 sentul Kabupaten Bogor.

\subsection{Koefisien Determinasi $\left(\mathrm{R}^{2}\right)$}

Koefisien derteminasi $\left(\mathrm{R}^{2}\right)$ berfungsi untuk mengetahui signifikasi variabel maka harus di cari koefisien derteminasi $\left(\mathrm{R}^{2}\right)$ koefisien derteminasi menunjukan besarnya konstrubusi variabel independen terhadap variabel dependen. Semakin besar nilai koefisiensi derteminasi, maka semakin baik kemampuan variabel independen menerangkan varibel dependen. Jika derteminasi (R2) semakin besar ( mendekati satu maka dapat di katakan bahwa pengaruh varibael independen adalah besar terhadap variabel depeden. Hal ini berarti, model yang di gunakan semakin kecil ( mendekati nol) maka dapat di katakan bahwa pengaruh variabel independen terhadap variabel dependen semakin kecil. Hal ini berarti, model yang di gunakan tidak kuat untuk menerangkan pengaruh variabel independen terhadap dependen.

Tabel 9. Hasil Uji Koefisien Determinasi

\begin{tabular}{|l|r|r|r|}
\hline \multicolumn{4}{|c}{ Model Summary $^{\text {b }}$} \\
\hline R & R Square & $\begin{array}{c}\text { Adjusted R } \\
\text { Square }\end{array}$ & $\begin{array}{c}\text { Std. Error } \\
\text { of the } \\
\text { Estimate }\end{array}$ \\
\hline, $652^{\mathrm{a}}$ & 0,425 & 0,406 & 0,772 \\
\hline
\end{tabular}

a. Predictors: (Constant), X3, X2, X1

b. Dependent Variable: Y

Sumber : Pengolahan Data, 2019

Berdasarkan uji kofisiensi derteminasi di atas di peroleh nilai Adjusted R square dari variabel persepsi kemudahan, persepsi manfaat, persepsi keamanan dan keputusan pembelian memiliki pengaruh sebesar 0,406 atau $40,6 \%$ sedangkan sisanyaa $59,4 \%$ di pengaruhi oleh variabel lain yang dalam penelitian ini tidak di teliti.

\subsection{Uji Parsial (Uji t)}

Uji ini digunakan untuk mengetahui apakah masing-masing variabel bebas secara individual berpengaruh signifikan terhadap variabel terikat. Pengujian dilakukan dengan membandingkan an-tara nilai t hitung masing-masing variabel bebas dengan nilai $t$ tabel dengan peluang kesalahan $10 \%(\mathrm{a}=0,1)$.

\section{Tabel 10. Hasil Uji t}

\begin{tabular}{|c|c|c|c|c|c|c|}
\hline \multicolumn{7}{|c|}{ Coefficients $^{\mathrm{a}}$} \\
\hline & \multirow{2}{*}{ Model } & \multicolumn{2}{|c|}{$\begin{array}{l}\text { Unstandardized } \\
\text { Coefficients }\end{array}$} & \multirow{2}{*}{\begin{tabular}{|c|}
$\begin{array}{c}\text { Standardized } \\
\text { Coefficients }\end{array}$ \\
Beta \\
\end{tabular}} & \multirow{2}{*}{$\mathrm{t}$} & \multirow{2}{*}{ Sig. } \\
\hline & & B & $\begin{array}{l}\text { Std. } \\
\text { Error }\end{array}$ & & & \\
\hline \multirow[t]{4}{*}{1} & (Constant) & 2,902 &, 692 & & 4,196 &, 000 \\
\hline & $\mathrm{X} 1$ &, 168 &, 045 &, 342 & 3,703 &, 000 \\
\hline & $\mathrm{x} 2$ &, 098 &, 055 &, 158 & 1,787 &, 077 \\
\hline & $\mathrm{X} 3$ &, 168 & .047 &, 324 & 3,588 &, 001 \\
\hline
\end{tabular}

Sumber : Pengolahan Data, 2019

Untuk menguji model regresi untuk masing-masing variabel secara parasial 
dapat di peroleh dengan menggunakan uji $\mathrm{t}$ berikut ini akan di jelaskan analisa masingmasing variabel :

1. Variabel Persepsi Kemudahan

Nilai signifikasi variabel persepsi kemudahan (X1) adalah $0,00<0,1$ berdasarkan hasil tersebut, maka di nyatakan $\mathrm{H} 0$ di tolak dan $\mathrm{H} 1$ diterima, dengan hal ini variabel persepsi kemudahan berpengaruh secara signifikan terhadap keputusan pembelian kartu Indomaret, di rest area stopan sentul.

\section{Variabel Persepsi Manfaat}

Nilai siginifikasi variabel persepsi manfaat $(\mathrm{X} 2)$ adalah $0,077<0,1$ berdasarkan hasil tersebut, maka di nyatakan Ho di tolak dan $\mathrm{H} 2$ di terima, dengan hal ini variabel persepsi manfaat berpengaruh secara signifikan terhadap keputusan pembelian kartu Indomaret, di rest area stopan sentul.

3. Variabel Persepsi Keamanan

Nilai signifikasi variabel persepsi keamanan (X3) adalah $0,01<0,1$ berdasarkan hasil tersebut, maka di nyatakan $\mathrm{H} 0$ di tolak dan $\mathrm{H} 3$ di terima, dengan hal ini variabel persepsi keamanan berpengaruh secara signifikan terhadap keputusan pembelian kartu Indomaret, di rest area stopan sentul.

\subsection{Uji Silmutan (Uji F)}

Pengujian ini bertujuan untuk mengetahui pengaruh variabel persepsi kemudahan, manfaat dan keamanan terhadap keputusan pembelian kartu Indomaret secara bersama-sama (simultan) variabel tersebut akan terbukti berpengaruh secara signifikan terhadap keputusan pembelian kartu indomaret jika nilai signifian kurang dari 0,1 kriteria pengambilan keputusan :

a. Ho diterima, apabila $\mathrm{F}$ hitung $<\mathrm{F}$ tabel pada $a=0,1$.

b. Ha diterima, apabila $\mathrm{F}$ hitung $>\mathrm{F}$ tabel pada $\mathrm{a}=0,1$.
Tabel 11. Hasil Uji F

\begin{tabular}{|c|c|c|c|c|c|c|}
\hline \multicolumn{7}{|c|}{ ANOVA $^{\mathrm{a}}$} \\
\hline \multicolumn{2}{|c|}{ Model } & $\begin{array}{l}\text { Sum of } \\
\text { Squares }\end{array}$ & Df & $\begin{array}{l}\text { Mean } \\
\text { Square }\end{array}$ & F & Sig. \\
\hline 1 & Regression & 40,433 & 3 & 13,478 & 22,624 &, $000^{6}$ \\
\hline & Residual & 54,806 & 92 &, 596 & & \\
\hline & Total & 95,240 & 95 & & & \\
\hline
\end{tabular}

Sumber : Pengolahan Data, 2019

Pada tabel diatas nilai $\mathrm{F}$ hitung 22,624 dan nilai $\mathrm{F}$ tabel $(\mathrm{df}=\mathrm{k}-1 \mathrm{df}=\mathrm{n}-\mathrm{k})$ pada tahap signifikasi 0,1 (F 0,1 (3) (92) $=2,14$, menunjukan nilai signifikan sebesar 0,000 dengan tingka kesalahan 0,1 .

Dapat di simpulkan bahwa F hitung > F tabel $(22,624>2,14)$ dengan tingkat probabilitas 0,000 (signifikan) dan dan probabilitas jauh lebih kecil dari 0,1 maka H4 diterima dan Ho di tolak.

Hal ini berarti terdapat pengaruh secara signifikan antara persepsi kemudahan, keamanan dan manfaat terhadap keputusan pembelian kartu indomaret di rest area stopan sentul.

\section{KESIMPULAN DAN SARAN}

\subsection{Kesimpulan}

Kesimpulan dalam penelitian ini adalah sebagai berikut :

1. Berdasarkan hasil uji thitung 3,703 > t tabel 1.66159 di ketahui variabel Persepsi Kemudahan Berpengaruh Signifikan Terhadap Keputusan Pembelian Kartu Indomaret di Rest Area KM 35 Sentul Kabupaten Bogor.

2. Berdasarkan hasil uji t hitung 1,787 > t tabel 1.66159 di ketahui variabel Persepsi Manfaat Berpengaruh Signifikan Terhadap Keputusan Pembelian Kartu Indomaret di Rest Area KM 35 Sentul Kabupaten Bogor.

3. Berdasarkan hasil uji t hitung 3,588 >t tabel 1.66159 diketahui variabel Persepsi Keamanan Berpengaruh Signifikan Terhadap Keputusan Pembelian Kartu Indomaret di Rest Area KM 35 Sentul Kabupaten Bogor. 
4. Berdasarkan uji F persepsi kemudahan, Manfaat dan keamanan secara Simultan berpengaruh signifikan terhadap keputusan pembelian kartu Indomaret di Rest Area KM 35 Sentul Kabupaten Bogor.

5. Hasil perhitungan regresi dapat di ketahui bahwa koefisien derteminasi (Adjust $R$ Square) yang di peroleh sebesar 40,6\% keputusan pembelian Kartu Indomaret di Rest Area KM 35 Sentul Kabupaten Bogor di pengaruhi oleh persepsi kemudahan, manfaat dan keamanan sedangkan sisanya 59,4\% keputusan pembelian kartu Indomaret di Rest Area KM 35 Sentul Kabupaten Bogor di pengaruhi faktor lain.

\subsection{Saran}

Dari hasil penelitian dapat diketahui bahwa saran yang dapat diberikan dalam penelitian ini yaitu:

1. Persepsi kemudahan, persepsi manfaat, dan keamanan yang di harapkan lebih bisa di tingkatkan lagi, agar konsumen yang berbelanja lebih di mudahkan dengan kartu indomaret dan volume pembelanjaan banyak agar brand indomaret penggunaan kartu indomaret berada di tingkat paling atas.

2. Riset ini di harapkan menjadi dasar peneliian yang akan di lakukan selajutnya. Bagi pihak yang ingin meneliti lebih lanjut, dapat menggunakan atau menambahkan variabel-variabel lain yang dapat mempengaruhi keputusan penggunaan kartu Indomaret.

\section{DAFTAR PUSTAKA}

Achmad, z. (2012). aplikasi pemasaran dan salesman. jakarta: mitra.

$\mathrm{Al}$, e. (2011). a theory of quality management.

Arista Ika Adiyanti (2015 ) “ Pengaruh Pendapatan, Manfaat Kemudahan Penggunaan, Daya Tarik Promosi dan
Kepercayaan Terhadap Minat Menggunakan Layanan E-money.

Basrah. (2012). Pengaruh Kualitas Produk dan Kualitas Pelayanan Terhadap Kepuasan Konsumen dan Minat Beli. Riset Manajemen Sains, Vol. 3 No 1.

Dewi Sinarwati (2017) "Pengaruh Persepsi Kebermanfaatan Kemudahan Kegunaaan dan Keamanan Terhadap Minat Meggunakan E-Banking.

Erfanto linangkung. http ://ekbis.sindonews.com/read/1132835/ 178/e-money- masih-minim-sri-sultanminta-bi-buat-kebijakan-khusus1471768002 , di akses pada 2 februari 2019.

Fahmi Natigor Nasution (2014) “ Pengaruh Persepsi Manfaat, Persepsi Kemudahan, Persepsi Kenyamanan, Dan Norma Subjektif Terhadap Minat Menggunakan Elektonik Commerce (Behavior Aspect) " USU Digital library.

Husain, U. (2011). Metode Penelitian. Yogyakarta: Jakarta.

Laksana Astuti (2015 ) “ Pengaruh Persepsi Kemanfaatan, Persepsi Kemudahan, Persepsi Resiko dan Persepsi Kesesuaian berpengaruh terhadap minat menggunakan mobile banking.

Solomon. (2011). Consumer Behavior. Jakarta: PT Gramedia Pustaka Utama.

Suharno. (2017 ). Marketing In Practice. Yogyakarta: Graha Ilmu.

Viswanathan. (2011). Web Services And S A Shooping A Study On Malaysian. IJCA, 54-60.

Yolanda. (2013). Metode Penelitian. Yogyakarta: Pustaka Belajar. 